\title{
A study to assess the chemical composition and antibacterial properties of honey.
}

\author{
Jerlin Priya Lovelin Auguskani* \\ Jazan University, Jazan, Kingdom of Saudi Arabia
}

\begin{abstract}
The present study was to assess the chemical composition and antibacterial properties of honey. From ancient times, honey was increasingly used as a remedy for wound healing. Globally, several studies have been conducted and proved that there are a numerous ways that honey can heal the wound. To accept that honey has medical property in wound healing there is limited evidence. Hence the researcher was interested to determine the chemical composition and anti-bacterial properties of honey. It was assumed that honey has antimicrobial, anti-oxidant, anti-inflammatory properties as per the literature review. Also is acidic with high osmolality. Honey also has an antioxidant property that protects the cells from free radicals. Clinically topical application of honey possess antimicrobial properties, promote autolytic debridement, deodorize malodorous wounds, stimulate growth of wound tissues to fasten healing, stimulate anti-inflammatory activity and promote moist wound healing. Thus the use of honey can be effective and economical approach to managing large wounds. An experimental approach is carried out to fulfil the objective in a controlled setting. Whole honey has been sent to the laboratory for compound isolation through column chromatography. Three compounds have been isolated namely compounds (1-3). The isolated compound along with whole honey and standard antibiotics were send to the clinical laboratory for antibacterial study with selected pathogens. The results showed compound-2 had a good antibacterial effect against pathogens like $E$. coli, Klebsiella, Staphylococcus albus, Staphylococcus aureus while comparing with compound 1 and compound 2. Against Pseudomonas the compound has no effective antibacterial effect. Hence it is concluded that honey can be a potential treatment for diabetic foot ulcer caused by pathogens.
\end{abstract}

Keywords: Anti-bacterial, Antioxidant, Healing, Wound, Staphylococcus, Honey, Chemical.

Accepted on August 01, 2018

\section{Introduction}

According to evidence found by anthropologist, Egyptians had used this approach 5000 years ago [1]. The anti-bacterial activity in vitro and the supporting empirical studies show that use of honey over the wound clears severely affected infection. The possession of anti-inflammatory activity and activation of immune responses by honey are indicated in the research [2] The quality of dehydrating the bacteria and its high acidity demonstrates the microbe killing ability of honey. Doctors have been willing to perform honey dressing, as many bacteria are becoming increasingly resistant to antibiotics. Peter studied on honey's properties in skin and wound care and found that honey is effective for diabetic ulcers [3]. Several clinical trials and hundreds of case reports have been cited by the researcher [2]. Honey is shown to be very effective against resistant bacteria in laboratory as well as in clinical studies. The present study aimed to determine the chemical composition and antibacterial properties of honey.

As much as it has the antioxidant property, it is also a potent anti-inflammatory agent to alleviate inflammation. Stimulation of angiogenesis and the growth of fibroblasts and epithelial cells, and its insulin-mimetic effect stimulates diabetic ulcer healing. A good healing rate can be achieved by the availability of honey impregnated dressings. The honey dressing keeps the ulcer clean and prevents infection that occurs with ischemic ulcers [3]. It was already found by many scientists that, honey has most powerful inhibitory effect with regard to sixty species of bacteria. Among them, many bacteria are resistant towards antibiotics but not towards honey. Because, it is nontoxic and will not produce any adverse effects. Moreover it is inexpensive, readily available and can be used by anyone. Honey acts a dry sponge that absorbs the water by the process of osmosis. Hence the infected exudates are drawn away thereby it destroys and minimizes the bacterial growth [4]. Hydrogen peroxide is available in honey naturally by means of an enzyme glucose oxidase. Therapeutically honey should be raw and unpasteurized, as pasteurization destroys the enzymes that are producing hydrogen peroxide. Carotenoids and phytosterol are the chemical compounds found in the plants which are collected by the bees. The phyto chemical property and chemical property vary from plant to 
plant. Researchers found that honey stimulate the release of a variety of cytokines including tumor necrosis factor, a protein that minimizes tissue inflammation and activates white blood cells, which is vital to healing [5].

It was assumed that honey has the antimicrobial activity called as "inhidine" which is hydrogen peroxide formed by glucose oxidise system. The antioxidant properties of honey reduce the risk of tissue oxidative damage. High osmolarity of honey leads to fluid outflow to create layer of dilute solution of honey in plasma resulting in moist conditions necessary for healing and no adhesion to the surface of the wound and clears debris. Honey is acidic in nature hence acts as antimicrobial agent. Honey has anti-inflammatory properties hence reduces pain. Lack of oxygen and vital nutrients causes delayed wound healing as honey is a natural fructose-glucose carbohydrate mixture, protein, vitamins and minerals hence fastens wound healing.

Peter studied on honey's properties in skin and wound care and found that honey is effective for diabetic ulcers [6]. Several clinical trials and hundreds of case reports have been cited by the researcher [7-27]. Honey is shown to be very effective against resistant bacteria in laboratory as well as in clinical studies. As much as it has the antioxidant property, it is also a potent anti-inflammatory agent to alleviate inflammation. Stimulation of angiogenesis and the growth of fibroblasts and epithelial cells, and its insulin-mimetic effect stimulates diabetic ulcer healing. A good healing rate can be achieved by the availability of honey impregnated dressings. The honey dressing keeps the ulcer clean and prevents infection that occurs with ischemic ulcers [3].

Asadullah et al. [28] conducted a study to find out the effectiveness of topical wound dressings in diabetic wounds with natural honey and mentioned that many studies have demonstrated that honey has antibacterial activity in vitro, and a small number of clinical case studies have shown that application of honey to severely infected cutaneous wounds which is capable of clearing infection from the wound and improving tissue healing.

Yasunori et al. [29] conducted a study to assess the antibacterial activity of honey against community-associated methicillin-resistant Staphylococcus aureus (CA-MRSA). CAMRSA (n1/4 6 isolates), was examined for its susceptibility to natural honey (n1/4 3 honey produced from bees in Northern Ireland and one commercial French honey). Results demonstrated that all honey was able to reduce the cultural count of all CA-MRSA from approximately $10^{6}$ colonyforming units (mean1/4 $6.46 \log 10 \mathrm{CFU} / \mathrm{g}$ ) to none detectable within $24 \mathrm{~h}$ co-culture of separate CA-MRSA organisms individually with all four-honey types examined. Subsequent non-selective enrichment of honey demonstrated that inoculated honey remained positive for CA-MRSA until $72 \mathrm{~h}$ post inoculation, after which point no cultural organisms could be detected. This study demonstrated that, in vitro, these natural products had an antimicrobial activity against the CAMRSA organisms tested. Further studies are now required to demonstrate if this antimicrobial activity has any clinical application.

The anti-bacterial activity in vitro and the supporting empirical studies showed that use of honey over the wound clears severely affected infection. The possession of antiinflammatory activity and activation of immune responses by honey are indicated in the research [1]. It was already found by many scientists that, honey has most powerful inhibitory effect with regard to sixty species of bacteria. Among them, many bacteria are resistant towards antibiotics but not towards honey. It also becomes an accepted component in Government recognized therapeutic ointment, lozenges and wound dressing products.

Foot ulcers result in lack of feeling in foot, poor blood circulation, foot deformities, irritation and trauma. In spite of the marvellous advances witnessed in the field of clinical science no sure cure for foot ulcer has so far been innovated. Numerous trial blessing innovative and explorative researchers are being carried out on diabetic foot ulcers and the methods of curing them from time immemorial. For a disease have been attained all possible attempts by scientist and doctors to subject it to problem free and patient friendly treatment. The investigator who has been tremendously influenced by the plethora of research monographs available on wound healing and effects of honey on wound healing, have initiated to do a research on effects of honey on diabetic wound healing.

\section{Materials and Methods}

The researcher evaluated chemical composition and antibacterial properties of honey using following methods.

\section{Data pertaining to chemical composition of honey}

Chemical composition and anti-bacterial properties of honey was determined using selective bio chemical assay and it was found that honey is a reliable source to enhance wound healing, minimize wound infection and pain.

\section{Compound isolation of honey}

Natural products, such as plants extract, either as pure compounds or as standardized extracts, provide unlimited opportunities for new drug discoveries because of the unmatched availability of chemical diversity. According to the World Health Organization (WHO), nearly 20,000 medicinal plants exist in 91 countries including 12 mega biodiversity countries. The premier steps to utilize the biologically active compound from plant resources are extraction, pharmacological screening, isolation and characterization of bioactive compound, toxicological evaluation and clinical evaluation.

\section{Procedure}

Column chromatography: The scheme of the work is as follows: 
Extraction of compounds: The honey was mixed with methanol and extracted in soxhlet apparatus kept overnight. The solvent layer was concentrated using Rotor vac. The concentrated extract was now ready for isolation.

Isolation using column chromatography: $30 \mathrm{~g}$ of crude was mixed with $60 \mathrm{~g}$ of silica gel (60-120 mesh) to made ad mixture. 2.4 dia column was packed with the admixture mixed with hexane. The column was eluted with increasing solvent polarity from hexane to ethyl acetate.

Fractionation of the methanol extract: Activated silica gel (60-120 mesh) was packed onto a glass column using n-hexane solvent. The methanol extract was loaded on top of the silica gel and eluted step-wise: $300 \mathrm{ml}$ of hexane, $500 \mathrm{ml}$ of hexane:ethyl acetate $(98: 2), 600 \mathrm{ml}$ of hexane: ethyl acetate (95:5), $800 \mathrm{ml}$ of hexane:ethylacetate $(85: 15)$ and $500 \mathrm{ml}$ of hexane:ethylacetate $(80: 20), 500 \mathrm{ml}$ of hexane:ethylacetate (75:25), $550 \mathrm{ml}$ of hexane:ethyl acetate (70:30), $200 \mathrm{ml}$ of ethyl acetate $(0: 100 \mathrm{v} / \mathrm{v})$. About 236 fractions were collected and concentrated by using the rotary evaporator.

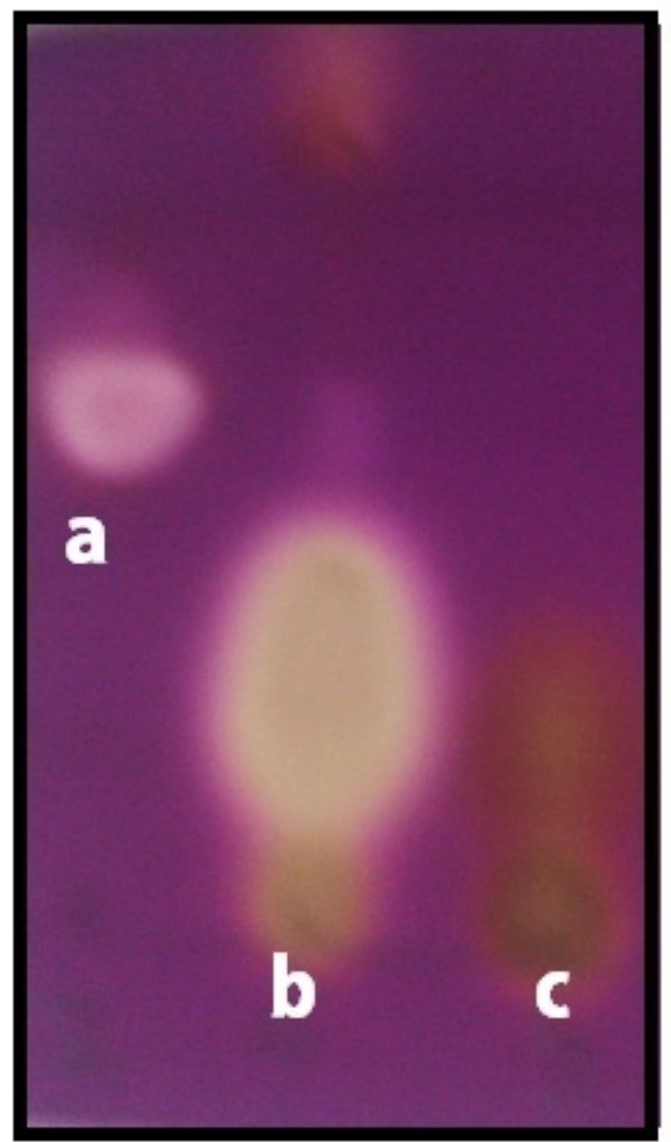

Figure 1. Thin layer chromatography showing isolated compounds of honey.

\section{Thin-layer chromatography (TLC)}

An aliquot of all the concentrated fractions was loaded on the activated silica gel TLC plates $(20 \times 20 \mathrm{~cm})$. The plates were developed using different ratio of hexane:ethyl acetate like 90:10, 75:25, 50:50 and 25:75. Spots were located by exposing the plate to iodine fumes and vanillin (Figure 1). Fractions having the same number of spots with similar $\mathrm{Rf}$ values on the TLC plate were pooled and got three fractions. Three fractions showed a major quantity and taken for spectrum studies. The isolated compounds from honey include

(Fraction a) compound $1=200 \mathrm{mg}$

(Fraction b) compound $2=160 \mathrm{mg}$

(Fraction c) compound $3=80 \mathrm{mg}$

The researcher used those compounds for analyzing antibacterial properties of honey.

\section{Data on sensitivity of honey, isolated compounds of honey and standard antibiotics with selected aerobic bacteria}

The researcher identifies the antibacterial properties of honey with isolated compounds derived from honey, selected antibiotics. The antibacterial effect of honey refers to the experiment that identify the effect of honey on different bacteria growing on agar plates in order to find out the properties present in the honey that help to destroy the pathogenic bacteria as measured by Kirby Bauer method.

\section{Procedure}

Samples were collected after the wounds are washed vigorously with normal saline solution. Using sterile swabs (Hi media), the fresh wound area from the margins and edges of an ulcer were wiped with the cotton swab. The wound swabs were then transported to the laboratory for culture. Then, using various differentials and selective media, the samples were cultured aerobically and an aerobically and bacterial pathogens were isolated using standard biochemical tests like Catalase coagulase oxidase test, Indole MR-VP test, Citrate test, TSI test.

Staining: This includes the microscopic appearance of a stained preparation of the wound swab using differential staining procedures is used. A gram stained film prepared from wound swabs and from culture were observed.

Plating: The collected swabs are subjected for observation by gram staining and isolation by aerobic and anaerobic culturing using standard techniques and media.

Aerobic isolation: Collected swabs were streaked over appropriate media. The media used are nutrient agar, mac conkey agar, blood agar. The streaked plates were incubated at $37^{\circ} \mathrm{C}$ for $24 \mathrm{~h}$. After incubation, the plates were observed for growth and the isolated colonies were identified by morphological by gram staining. Bacterial pathogens were 
identified by conventional biochemical methods according to standard microbiological techniques (Kelly).

Anaerobic isolation: Swabs with pus were inoculated in freshly prepared tubes of Robertson cooked meat broth. The top layer of the media is covered with melted paraffin wax, So that oxygen entering into the media is prevented. The top of the tube is cotton plugged and was again dipped in wax. The tubes were incubated in $37^{\circ} \mathrm{C}$ for $3 \mathrm{~d}$ in order to identify the growth of saccarolytic, proteolytic anaerobes.

Table 1. Data on sensitivity of honey, isolated compounds of honey and standard antibiotics with selected aerobic bacteria.

\begin{tabular}{|c|c|c|c|c|c|}
\hline \multirow[b]{2}{*}{ Compound } & \multicolumn{5}{|c|}{ Aerobic bacteria } \\
\hline & E. coli & Klebsiella & Staphylococcus aureus & Pseudomonas & Staphylococcus albus \\
\hline Whole honey & 18 & 17 & 22 & 18 & 20 \\
\hline Compound 1 & 3 & 3 & 2 & 4 & 3 \\
\hline Compound 2 & 14 & 13 & 14 & 4 & 14 \\
\hline Compound 3 & 4 & 3 & 4 & 3 & 4 \\
\hline Standard antibiotics & 20 & 22 & 18 & 18 & 20 \\
\hline
\end{tabular}

Zone of inhibition: Resistant=0-5, Moderate sensitivity=6-15, Sensitive=16-30.

Table 1 showed the comparative value antibacterial effect of compounds (1-3) isolated from whole honey along with a standard antibiotic and whole honey. The results showed compound-2 had a good antibacterial effect against pathogens like E. coli, Klebsiella, Staphylococcus albus, Staphylococcus aureus while comparing with compound 1 and compound 2 . Against Pseudomonas the compound has no effective antibacterial effect (Figures 2-7).

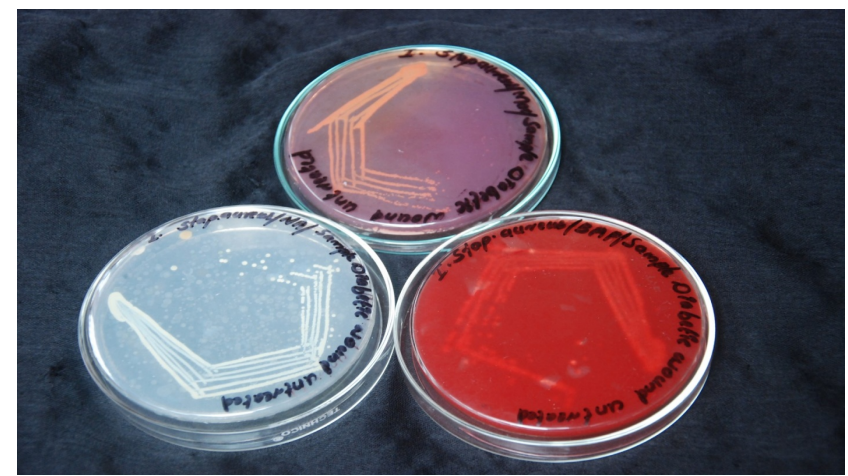

Figure 2. Staphylococcus aureus isolated from untreated wound.

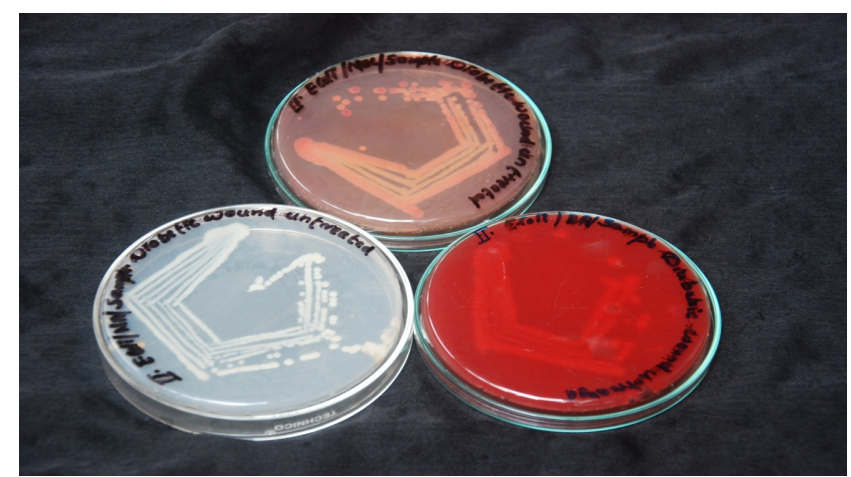

Figure 3. E. coli isolated from untreated wound.

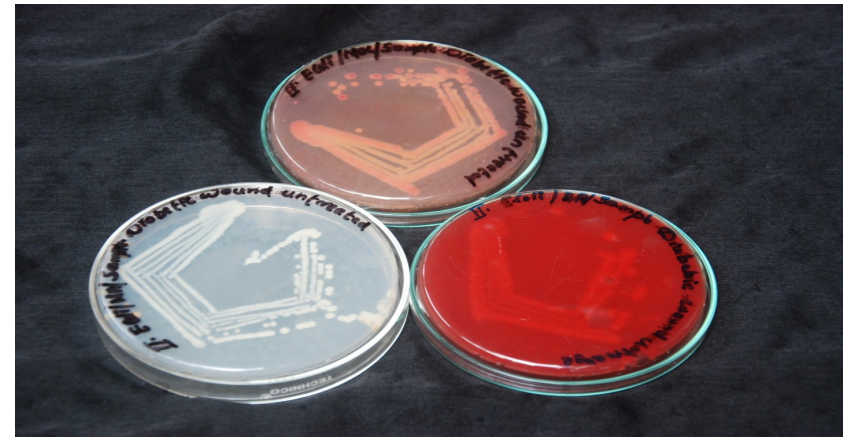

Figure 4. Klebsiella isolated from untreated wound.

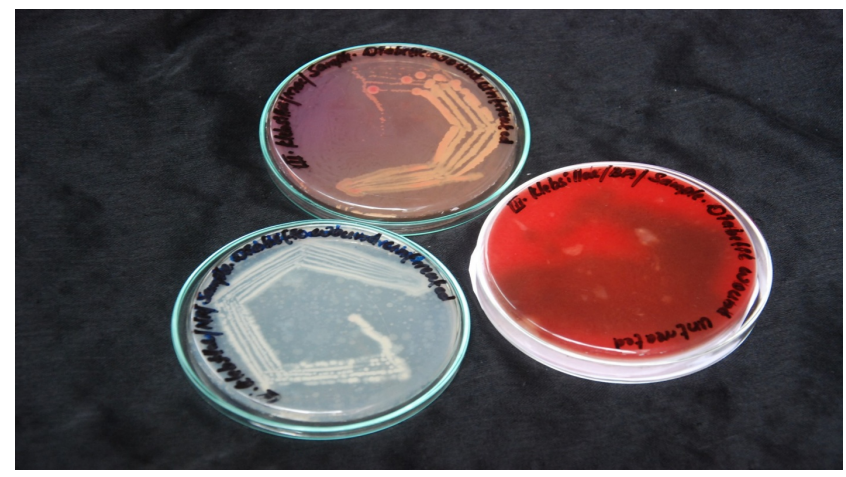

Figure 5. Pseudomonas isolated from untreated wound.

\section{Discussion}

Honey is a sweet and flavourful natural product, which is consumed for its high nutritive value and for its effects on human health, with antioxidant, bacteriostatic, antiinflammatory and antimicrobial properties, as well as wound and sunburn healing effects.

This is an indication that honey can be a potential treatment for diabetic foot ulcer caused by pathogens. This is because low 
$\mathrm{pH}$ (3.5-4.5) of honey which inhibit Staphylococcus aureus growth, stimulate the bactericidal action of macrophages in chronic wounds and also suppress the production and propagation of inflammatory cells at the wound site. This may also stimulate the production of proinflammatory cytokine, allowing normal healing to occur and stimulating the proliferation of fibroblast and epithelial cells.

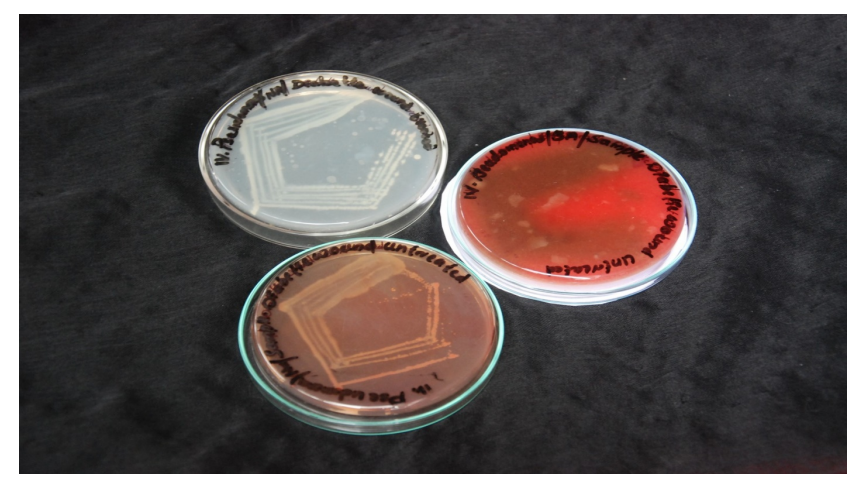

Figure 6. Staphylococcus albus isolated from untreated wound.

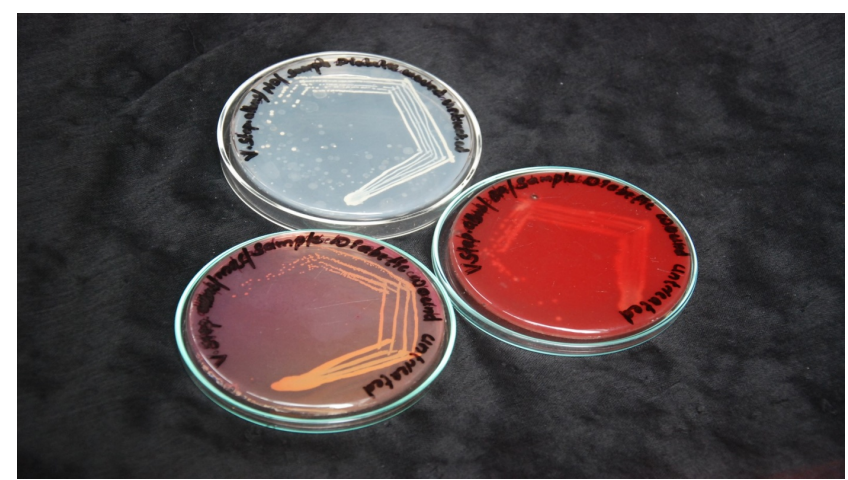

Figure 7. Sensitivity of honey, isolated compounds of honey and standard antibiotics with selected aerobic bacteria.

\section{Conclusion}

The results of the present study revealed that, honey dressing can be used as an effective non-pharmacological approach for wound healing thereby alleviating the wide range of complications developed due to diabetic foot ulcer. The study findings may help to consider that, honey is a natural wound healer with antimicrobial properties and is patient friendly in diabetic wound healing.

\section{References}

1. Stefan B. Honey in medicine. Bee Product Science 2014; $1-4$.

2. Vasantha KR. Case Study on Dr. Mohans Diabetes Specialties Centre-Nove 2010: 1-13.

3. Molan PC. Clinical usage of honey as a wound dressing. $\mathrm{J}$ Wound Care 2004; 13.

4. Molan PC. The evidence and the rationale for the use of honey as a wound dressing. Wound Pract Res 2011; 19: 204-220.
5. Molan PC. A brief review of the use of honey as a clinical dressing. The evidence for honey promoting wound healing. Aus J Wound Manag 1998; 148-158.

6. Molan PC. The role of honey in the management of wounds. J Wound Care 1999; 8: 415-418.

7. Patton T, Barrett J, Brennan J, Moran N. Use of a spectrophotometric bioassay for determination of microbial sensitivity to manuka honey. J Microbiol Methods 2006; 64: 84-95.

8. Cooper RA. Antibacterial activity of honey against strains of Staphylococcus aureus from infected wounds. J Royal Soc Med 1990; 92: 283-285.

9. Al-Waili NS. Investigating the antimicrobial activity of natural honey and its effects on the pathogenic bacterial infections of surgical wounds and conjunctiva. J Med Food 2004; 7: 210-222.

10. Estevinho L. Antioxidant and antimicrobial effects of phenolic compounds extracts of Northeast Portugal honey. Food Chem Toxicol 200; 46: 3774-3776.

11. Estevinho L, Pereira AP. Antioxidant and antimicrobial effects of phenolic compounds extracts of Northeast Portugal honey. Food Chem Toxicol 2008; 46: 3774-3779.

12. Mathews KA, Binnington AG. Wound management using honey. Compend Contin Educ Pract Veterin 2002; 24: 53-59.

13. Bansal V, Medhi B, Pandhi P. Honey-a remedy rediscovered and its therapeutic utility. Kathmandu Univ Med J 2005; 3: 305-309.

14. Wang PR. Phenolic compounds of Chromolaenaadorata protect cultured skin cells from oxidative damage: implication for cutaneous wound healing. Biol Pharm Bull 2004; 24: 1373-1379.

15. Molan PC. Re-introducing honey in the management of wounds and ulcers - theory and practice. Ostomy Wound Manage 2002; 48: 28-40.

16. Lusby PE, Coombes A, Wilkinson JM. Honey: a potent agent for wound healing? J Wound Ostomy Continence Nurs 2002; 29: 295-300.

17. Crane E. Honey-a comprehensive survey. Russak Crane Tex USA 1975.

18. Ryan GB, Majno G. Acute inflammation. a review. Am J Pathol 1997; 86: 183-276.

19. Vijaya KK1, Nishteswar K. Wound healing activity of honey: A pilot study. Ayu 2012; 33: 374-377.

20. Al-Waili NS, Salom K, Al-Ghamdi AA. Honey for wound healing, ulcers, and burns; data suorting its use in clinical practice. Sci World J 2011; 11: 766-787.

21. Eddy J, Gideonsen MD, Mack JP. Practical considerations of using topical honey for neuropathic diabetic foot ulcers: a review. Wisconsin Med J 2008; 107: 187-190.

22. Bang LM, Buntting C, Molan P. The effect of dilution on the rate of hydrogen peroxide production in honey and its implications for wound healing. J Alt Compl Med 2003; 9: $267-273$. 
23. Dunford C. The use of honey-derived dressings to promote effective wound management. Profess Nurse 2005; 20: 35-38.

24. Childress BB, Stechmiller JK. Role of nitric oxide in wound healing. Biol Res Nurs 2002; 4: 5-15.

25. Moncada R. Nitric oxide: physiology, pathophysiology, and pharmacology. Pharmacol Rev 2002; 43: 109-142.

26. Pieper B. Honey-based dressings and wound care: an option for care in the United States. J Wound Ostomy Continence Nurs 2009; 36: 60-66.

27. Phuapradit M, Saropala N. Topical alication of honey in treatment of abdominal wound disruption. Aus NZ J Obstetr Gynaecol 1992; 32: 381-384.

28. Makhdoom A, Khan MS, Lagahari MA, Rahopoto MQ, Tahir SM, Siddiqui KA. Management of diabetic foot by natural honey. J Ayub Med Coll Abbottabad 2009; 21: 103-105.

29. Yasunori M. Antibacterial activity of honey against community associated methicillin-resistant. Staphylococcus aureus (CA-MRSA) Compl Ther Clin Pract (14th Edn.). 2008; 77-82.

\section{"Correspondence to}

Jerlin Priya Lovelin Auguskani

Jazan University

Jazan

Kingdom of Saudi Arabia 